\title{
Population Ageing in India
}

\author{
edited by G. Giridhar, K.M. Sathyanarayana, \\ Sanjay Kumar, K.S. James, and Moneer Alam \\ Delhi: Cambridge University Press 2014 \\ ISBN 978-1-107-07332-6 \\ Hardcover $\$ 151.73,226$ pp.
}

\author{
Reviewed by Bali Ram \\ Department of Sociology and Anthropology, Carleton University, Ottawa \\ and Department of Sociology, Western University, London ON
}

Until recently, population aging - usually defined as the increasing share of older persons age 60 or older (and sometimes age 65 or older) in the population-was known as a phenomenon of the industrialized world. Now it is recognized as a global phenomenon. Almost all countries in the world, with the exception of the African continent, are experiencing growth in the number and proportions of older people in their populations. Population in the industrialized countries has been aging for quite some time. Today, more than one in four people in a number of countries are over the age of 60 years, with Japan (33 per cent), Germany (28 per cent), Italy (28 per cent), and Finland (27 per cent) being in the lead. Almost one-third of the population in the industrialized world is expected to be in the older age groups by 2050. India is still far behind in this race. Today, just about 10 per cent of India's population is 60 years or older, and this figure is not expected to exceed 20 per cent by 2050. However, the sheer number of older people—about 315 million-will have a profound impact on nearly all facets of society, particularly health and long-term care and old-age income security systems, which are still relatively underdeveloped in India. Given the relative dearth of Indian studies that would help develop evidence-based policies to meet the challenges of population aging, this book is a welcome addition to the growing body of literature on the subject.

This volume begins with a general overview chapter by Giridhar, Sathyanarayana, and James, which largely sets the tone of the chapters that follow. According to these authors, the book is intended to bring together the available evidence from existing secondary data for developing a good knowledge base on the lives and living conditions of the elderly and to provide useful policy and program insights. Also, it is supposed to focus on the vulnerabilities of older people, especially women. To some extent, the book endeavours to address these issues, though not necessarily in a comprehensive manner. In their lead article on demographics of population aging, Subaiya and Bansod (Chapter 1), present detailed Census data and population projections that offer a numerical picture of changing patterns of aging at the national and state levels. This 8-page article, which contains 4 tables, 9 figures, and 12 Appendix tables is highly simplistic in describing and explaining major trends of population aging. One key piece of demographic information that is not adequately addressed concerns the roles of declines in fertility and increases in life expectancy - the two major determinants of aging process. The fact that fertility decline is the primary factor behind population aging in India, while improved longevity plays a minor role is discussed only in passing.

Selected economic characteristics of the older population are examined in Chapter 2. Using data from various rounds of the Employment and Unemployment Surveys (National Sample Survey), Selvaraj, Karan, and Madheswaran highlight the economic vulnerability of older people. For example, they show that well over half of men and one-fifth of women aged 60 years and over are in the labour force-a phenomenon that has 
changed little over the past three decades, particularly in rural areas where the rates are even higher (64 per cent for males and 25 per cent for females in 2004-05). The vulnerability of older people is also apparent in wage statistics. While the daily real wage rate (in constant 1993-94 prices) for older men increased from Rs. 59 in 1987-88 to Rs. 90 in 2004-05, it remained virtually unchanged for women at around Rs. 35 during the same period. This chapter does not provide any information at the state level.

Sathyanarayana, Kumar, and James (Chapter 3) present a highly illuminating picture of changes in the living arrangement patterns of the elderly. We learn that population aging is particularly pronounced among women, resulting in the feminization of aging and preponderance of older women—often widows-living alone. We also learn about the declining prevalence of older couples living with their children and grandchildren, and the increasing prevalence of older people living with a spouse only. The authors use only first and third waves of the National Family Health Survey and ignore the second wave. The data for all three waves would have been more useful in charting out living arrangement trends. As the authors state, they do not use Census data—an ideal source for studying trends and patterns of living arrangement- because unit-level Census data are not available. However, they could have used Census data on sex ratio among older people for examining feminization of aging, and on marital status for studying the rise in widowhood in older ages. Census data could have also allowed the analysis of widowhood and feminization of aging at the state level.

In Chapter 4, Alam and Karan make diligent use of data from the National Sample Surveys in describing and explaining various facets of health status of older people. Surprisingly, they do not provide any data at the state level, despite the fact there is enormous regional disparity in health conditions in India. Also, they do not discuss many important statistics by gender, such as death rates, life expectancy, incidence of diseases, self-perceived health status, or health care services utilization.

Rajan and Mishra (Chapter 5) present a critique of the National Policy for Older Persons (NPOP) formulated in 1999. The NPOP has "the primary objectives of encouraging individuals to make provision for their own as well as their spouse's old age; encouraging families to take care of their older family members; and creating in the elderly persons an awareness of the need to develop themselves into independent citizens" (p. 136). As the authors rightly point out, the NPOP has a "broad sweep" and is "difficult to implement with the limited organizational, financial and management resources" (p. 151). Thus, the inclusion of an article by Shankardass (Chapter 6) with a review of policy initiatives in a number of Asian countries such as Japan, Singapore, China, Malaysia, and Thailand is highly appropriate for appraising India's programs and policies on aging in a relative context. This chapter would certainly be beneficial to scholars and policy analysts, but it would have been much more useful had the author devoted some space to the exposition of demography and living conditions of older people in those countries. In the final Chapter 8, Siva Raju presents a comprehensive review of the literature on aging in India in order to show the gaps in this area of research. For example, he states that a majority of the studies conducted so far are "exploratory and descriptive," and "localized and based on sample surveys on specific segments of elderly." This chapter should have appeared immediately after the Introduction, or could have been part of the introduction.

Overall, this volume has four major shortcomings. First, most of the articles are highly descriptive, lacking in-depth analysis. The 226-page book includes 65 tables and 34 figures and is much like a compendium of statistics on aging in India. How aging and socioeconomic changes affect one another is discussed only superficially. Second, there is a serious lack of analyses based on individual-level data, although public-use microdata files from various surveys (e.g., National Family Health Survey) are readily available. In the absence of multivariate analyses based on individual-level data, it becomes difficult to disentangle underlying mechanisms through which the aging process and public policy affect demographic, economic, and health behaviours of the elderly. Third, there is a neglect of the use of available data in describing and explaining the conditions of the elderly. Except in Chapter 1, Census data have not been utilized in an appropriate manner. Data from the 2011 Census may not have been easily available to the authors by the time of the publication of this volume, but I wonder why data from the previous censuses were completely ignored, even when describing historical trends. Recently, the Government of India's Central Statistical Organization (2011) produced a very detailed study of the demographic, social, economic, and health conditions of the elderly, along with a description of national policies and programs for welfare of the elderly. Although the book under review was published three years later, it does not 
make concerted effort to make use of the rich data source. Finally, except for the chapter on policy initiatives in selected Asian countries, no other chapter includes any discussion on international comparison of population aging. So much international data on older people are now available from organizations such as United Nations, World Bank, and World Health Organization. Despite flaws and weaknesses, however, this book should serve well as a sourcebook for students, policy analysts, and policymakers. Hopefully, it will encourage researchers to undertake comprehensive studies on various facets of population aging.

\section{Reference}

Central Statistical Organization, Government of India. 2011. Situation Analysis of the Elderly in India. New Delhi: Central Statistical Office, Government of India. 